\title{
HIPERTENSÃO PORTAL
}

\author{
PORTAL HYPERTENSION
}

Ana L. Candolo Martinelli

Docente. Departamento de Clínica Médica. Faculdade de Medicina de Ribeirão Preto - USP

CorRespondência: Divisão de Gastroenterologia. Departamento de Clínica Médica. Faculdade de Medicina de Ribeirão Preto Hospital das Clínicas da Faculdade de Medicina de Ribeirão Preto - USP. Campus da USP - CEP 14049-900 Ribeirão Preto - SP, Brasil. Fone: 16- 602 2456/ Fax: 16-633 6695 e-mail: adlcmart@fmrp.usp.br

MARTINELLI ALC. Hipertensão portal. Medicina, Ribeirão Preto, 37: 253-261, jul./dez. 2004.

RESUMO: A hipertensão portal é uma síndrome clínica freqüente em nosso meio e acompanha-se de manifestações clínicas graves. Aqui são abordados alguns aspectos da hipertensão portal, com particular ênfase na fisiopatologia da síndrome e em suas manifestações clínicas. São listadas causas de hipertensão portal e discute-se a importância de informações obtidas durante a história clínica e no exame físico, que permitem o diagnóstico da síndrome e que auxiliam no esclarecimento da possível etiologia do processo.

UNITERMOS: Hipertensão Portal. Sistema Porta. Veia Porta.

\section{1- ANATOMIA DO SISTEMA VENOSO POR- TAL}

O sistema venoso portal (Figura 1) é constituído por veias que coletam o sangue da porção intra-abdominal do trato alimentar, baço, pâncreas e vesícula biliar.

A veia porta propriamente dita tem 6 a $8 \mathrm{~cm}$ de comprimento e é formada pela junção das veias esplênica e mesentérica superior. No hilo hepático, a veia porta divide-se em dois ramos, o direito, que supre de sangue o lobo direito do fígado, e o esquerdo, que leva sangue para os lobos esquerdo, caudado e quadrado. As veias esplênicas originam-se no hilo esplênico, unem-se com as veias gástricas curtas para formar a veia esplênica principal que recebe sangue da veia gastroepiplóica esquerda e de várias tributárias que drenam o pâncreas. A veia mesentérica inferior drena o sangue do cólon esquerdo e do reto e, geralmente, penetra no terço médio da veia esplênica. A veia gástrica esquerda, geralmente, une-se à veia porta, na sua origem, mas pode drenar para a veia esplênica. A veia mesentérica superior é formada por tributárias que drenam o lado direito do cólon, intestino delgado e cabeça do pâncreas. O sangue portal é levado pelos ramos terminais da veia porta até os sinusóides e, desses, para as veias centrolobulares que drenam para as veias hepáticas e estas para a veia cava inferior. A pressão portal normal é de 5 a 10 $\mathrm{mmHg}$, de acordo com o método empregado; considera-se hipertensão portal quando existe um aumento persistente da pressão portal acima desses níveis.

\section{2- ASPECTOS FISIOPATOLÓGICOS DA HI- PERTENSÃO PORTAL}

A pressão $(\Delta \mathrm{P})$ no sistema portal como em qualquer outro sistema vascular, é o resultado da interação entre o fluxo sangüíneo (Q) e a resistência vascular (R) que se opõe a esse fluxo; é representada matematicamente de acordo com a lei de Ohm como $\Delta \mathrm{P}=\mathrm{Q} x$ R. Assim, a pressão portal pode aumentar, se houver aumento do fluxo sangüíneo portal ou aumento da resistência vascular ou de ambos. (Figura 2). 


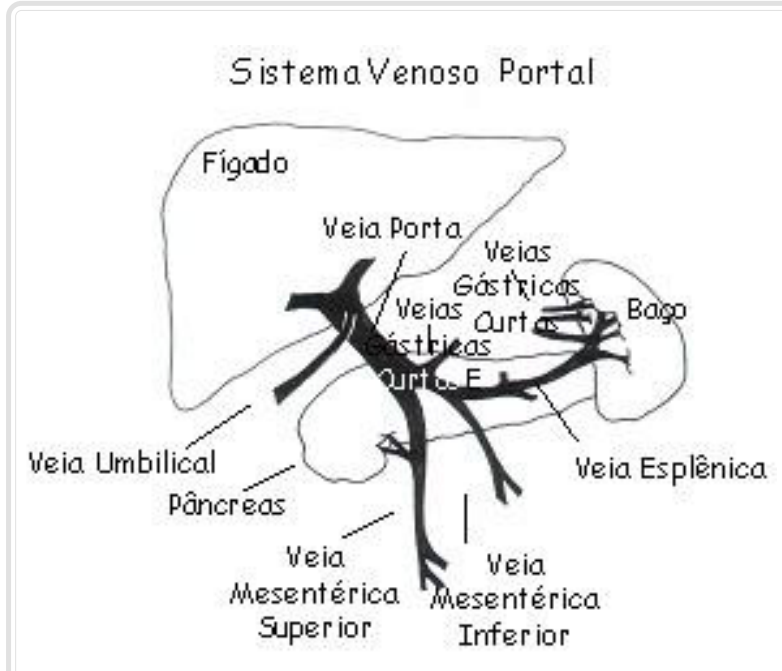

Figura 1: Modificado de Sherlock S \& Dooley J (2002).

\section{PRESSÃO PORTAL}

$$
\begin{aligned}
& \Delta P=Q \times R \\
& \Delta P=\text { gradiente de pressão portal } \\
& Q=\text { fluxo sangüíneo } \\
& R=\text { resistência }
\end{aligned}
$$

\section{HIPERTENSÃO PORTAL}

$$
\text { 1 } \triangle P=\boldsymbol{T} \times \mathbb{\top} R
$$

Figura 2: Pressão Portal. Lei de Ohm. Os dois componentes envolvidos na hipertensão portal.

Os fatores envolvidos no desenvolvimento e na manutenção da hipertensão portal não estão completamente esclarecidos. Na cirrose, é bem estabelecido que o fator primário, que leva à hipertensão portal, é o aumento da resistência vascular ao fluxo portal e que o aumento do fluxo se torna especialmente importante em fases mais avançadas da doença e contribui para a manutenção da hipertensão portal.

\section{1- Aumento da resistência}

O aumento da resistência pode ocorrer em qualquer ponto ao longo do sistema venoso, na veia porta, nos espaços vasculares dentro do fígado e nas veias e compartimentos vasculares que recebem o fluxo portal após sair do fígado. Em fases posteriores as cola- terais portossistêmicas passam a contribuir para o aumento da resistência.

Os fatores que influenciam a resistência vascular (R) são inter-relacionados pela lei de Poiselle, na equação: $\mathrm{R}=8 \mathrm{~mL} / \mathrm{r}^{4}$, onde $\mathrm{m}$ é o coeficiente de viscosidade do sangue, L é o comprimento do vaso e $r$ o raio do vaso. Sendo assim, o principal fator na determinação da resistência vascular é o raio do vaso.

A resistência aumentada do fluxo pode ser préhepática, pós-hepática e intra-hepáticas (Figura 3). Na pré-hepática, o aumento da resistência ocorre na veia porta ou tributárias antes de alcançar o fígado. Na póshepática, o aumento da resistência ocorre em veias ou compartimentos vasculares que recebem o fluxo sanguiíneo portal ao sair do fígado. $\mathrm{Na}$ intra-hepática, o aumento da resistência, tendo os sinusóides como referência, pode ser sinusoidal, pré-sinusoidal e póssinunoidal (Figura 4). As síndromes de resistência intrahepáticas são mais complexas e, raramente, podem ser classificadas de acordo com um único sítio de resistência. É comum que o aumento da resistência ocorra em várias áreas, e, se a doença progride, novos sítios podem ser envolvidos. O exemplo típico é a hipertensão portal que ocorre na hepatopatia crônica pelo álcool, onde o aumento da resistência é intra-hepático, principalmente sinusoidal (aumento do volume dos hepatócitos, deposição de colágeno nos espaços de Disse) e pós-sinusoidal (esclerose das veias centrolobulares) e, além disso, a presença dos nódulos de regeneração comprometem a drenagem sangüínea.

Reconhece-se o importante papel da alteração estrutural da microcirculação hepática (fibrose, capilarização dos sinusóides e nódulos de regeneração) como o mecanismo mais importante para o aumento da resistência vascular na cirrose, processo esse que, na maioria das vezes, é considerado irreversível. Assim, por muitos anos, pensou-se que a resistência vascular era fixa, conseqüência mecânica da distorção da arquitetura da microcirculação hepática. Recentemente (década de 80), esse conceito mudou, sendo demonstrado que, em associação com o componente mecânico da resistência vascular hepática, existe um componente dinâmico, que se deve ao aumento do tônus vascular (Figura 4). Como em qualquer outro endotélio vascular, a modulação da resistência depende da interação entre vasodilatadores e vasoconstrictores. Portanto, o aumento do tônus vascular pode resultar da diminuição de vasodilatores e/ou aumento de vasoconstrictores. Vale ressaltar que existem elementos contráteis no fígado que são capazes de se contra- 


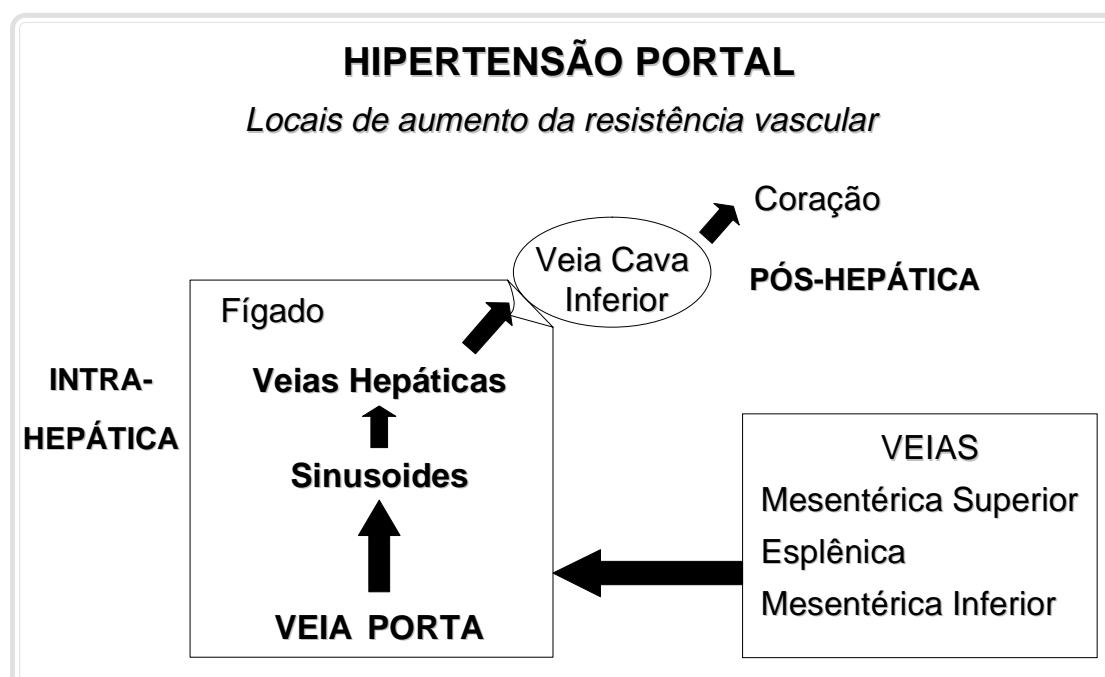

PRÉ-HEPÁTICA

Figura 3: Locais de aumento da resistência vascular tendo o fígado como referência.

\section{HIPERTENSÃO PORT AL}

\section{Classificação de acordo com o local de aumento da resistência vascular $(\mathbf{R})$}

R (resistência):

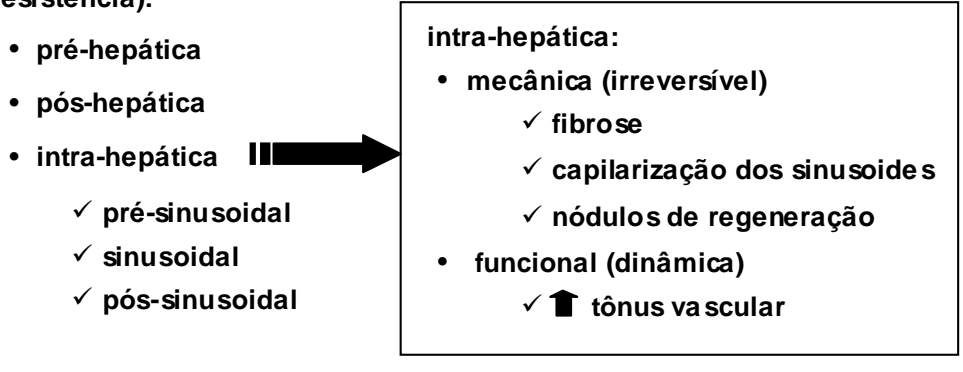

Figura 4: Classificação da hipertensão portal. Mecanismos de aumento de resistência intra-hepática.

mente. Os elementos contráteis podem estar localizados nos sinusóides (células estrelares ativadas) ou em sítios extra-sinusoidais (vasos contendo células musculares lisas contráteis como pequenas vênulas portais, vênulas présinusoidais e pós-sinusoidais). Recentemente, foi demonstrado que o endotélio vascular tem importante papel na regulação do tônus vascular por sintetizar substâncias vasoativas (vasodilatadores e vasoconstrictores), que agem de maneira parácrina em resposta a diferentes estímulos mecânicos e químicos. Fatores relativos à localização e às características das células estrelares sugerem sua participação na regulação da pressão portal e no aumento do tônus vascular na cirrose. Essas células localizam-se estrategicamente nos sinusóides (espaço de Disse), têm extensões que envolvem os sinusóides e os hepatócitos, quando ativadas adquirem propriedades contráteis semelhantes a miofibroblastos e têm receptores para substâncias vasoativas.

As substâncias vasoativas produzidas pelo endotélio vascular como vasodilatadores (prostaciclinas e óxido nítrico) e vasoconstrictores (endotelinas e prostanóides) agem de forma parácrina na musculatura lisa de vasos e nas células estrelares ati-

ir de maneira reversível em resposta a agonistas causando aumento da resistência vascular intra-hepática. Assim, parte do aumento da resistência pode ser diminuída por agentes farmacológicos indicando que essa porção intra-hepática do aumento da resistência não é fixa e que anormalidades funcionais têm importante papel na manutenção da hipertensão portal.

Do componente funcional participam células não parenquimatosas que produzem substâncias vasoativas ou sofrem os efeitos dessas substâncias vasoativas liberadas localmente ou produzidas sistemica- vadas e modulam o tônus vascular normal, o qual é mantido pelo balanço entre substâncias vasodilatadoras e vasoconstrictoras. A perturbação desse balanço leva a anormalidades no tônus vascular. Dentre as substâncias produzidas localmente pelas células endotelias, merecem destaque o óxido nítrico - NO (potente vasodilatador) e as endotelinas (potente vasoconstrictor). Vários estudos têm reforçado o papel das endotelinas na determinação da hipertensão portal. Por outro lado, o papel do NO, vasodilatador endógeno com importante papel na regulação fina do 
tônus vascular local, tem sido extensamente investigado. Estudos sugerem que na cirrose ocorre diminuição intra-hepática de $\mathrm{NO}$ e que esse seria o principal fator responsável pelo aumento da resistência vascular intra-hepática. Os mecanismos envolvidos na diminuição do NO intra-hepático ainda não estão totalmente elucidados.

Ressalta-se ainda o papel de vasoconstrictores circulantes como norepinefrina, angiotensina e vasopressina, usualmente aumentados na circulação de cirróticos.

Embora o fator primário no desencadeamento da hipertensão portal na cirrose seja o aumento da resistência vascular, o aumento do fluxo contribui para o aumento da pressão portal e para sua manutenção em níveis altos, aspecto que será discutido a seguir.

\section{2- Aumento do fluxo sangüíneo}

Na década de 80, a partir de trabalhos envolvendo modelos experimentais de hipertensão portal, o aumento do fluxo sangüíneo, como componente da hipertensão portal, passou a ser valorizado. $\mathrm{O}$ aumento do fluxo sangüíneo portal é conseqüente à vasodilatação em órgãos esplâncnicos, que drenam o sangue para a veia porta. A vasodilatação também ocorre na circulação sistêmica. Ressalta-se que a vasodilatação é o evento iniciador da circulação hiperdinâmica que é observada em estágios avançados de hipertensão portal (Figura 5). A circulação hiperdinâmica é caracterizada por diminuição da resistência vascular periférica, diminuição da pressão arterial média, expansão do volume plasmático, aumento do fluxo sangüíneo esplâncnico e aumento do débito cardíaco (Figura 6).

Os fatores envolvidos na determinação do aumento do fluxo sangüíneo não estão totalmente esclarecidos. Três mecanismos podem contribuir para a vasodilatação periférica, como aumento dos vasodilatadores circulantes, aumento da produção endotelial de vasodilatadores locais e diminuição da resposta a vasocontrictores endógenos, o último, provavelmente, sendo efeito dos dois primeiros.

\subsection{1- Aumento dos vasodilatadores circulantes}

Alguns estudos favorecem o papel de vasodilatadores esplâncnicos, cujos níveis podem estar aumentados em consequiência ao aumento da produção ou à diminuição da metabolização hepática quer pela presença de shunt portossistêmico ou por disfunção he-

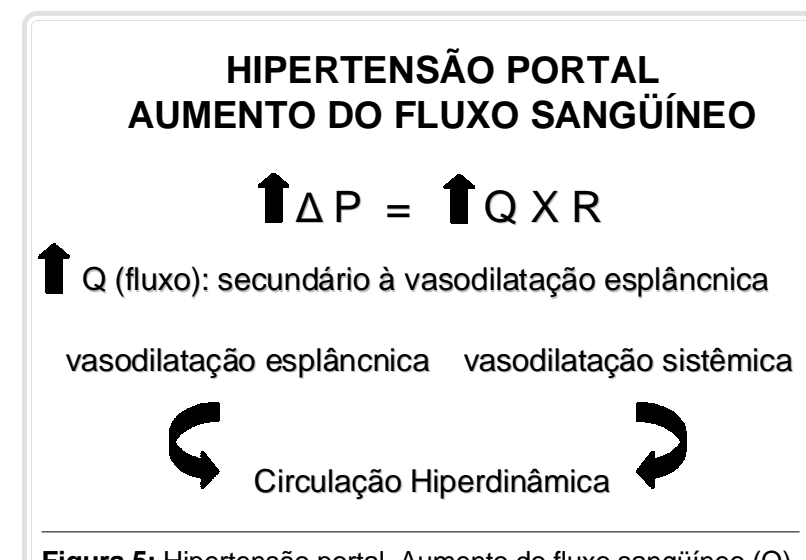

Figura 5: Hipertensão portal. Aumento do fluxo sangüíneo (Q).

\section{HIPERTENSÃO PORTAL}

Circulação Hiperdinâmica:

1 resistência vascular periférica

1 pressão arterial média

- volume plasmático

1 fluxo sangüíneo esplânc nico

1 débito cardíaco

Figura 6: Componentes da circulação hiperdinâmica.

pática. Acredita-se que possam ter participação o glucagon, os ácidos biliares e peptídeos vasodilatadores. Os níveis de glucagon estão aumentados na cirrose experimental e humana, e várias evidências sugerem sua participação na hiperemia esplâncnica.

\subsection{2- Aumento da produção endotelial de vaso- dilatadores locais}

Recentemente, importante papel de fatores vasoativos produzidos pelo endotélio vascular tais como NO e prostaciclinas, tem sido demonstrado na patogênese de anormalidades circulatórias associadas à hipertensão portal. Evidências apóiam o papel do NO, potente vasodilatador derivado do endotélio, na vasodilatação esplâncnica e sistêmica. Vários estudos têm dado suporte também à participação das prostaglandinas na vasodilatação que acompanha a hipertensão portal. 
A vasodilatação esplâncnica é associada à vasodilatação periférica e à manifestação de circulação sistêmica hipercinética. É provável que os mesmos mecanismos estejam envolvidos na circulação hipercinética de ambas, circulação esplâncnica e circulação sistêmica.

\subsection{3- Diminuição da resposta a vasoconstricto- res endógenos}

A hiporresponsividade a vasoconstrictores endógenos como norepinefrina, angiotensina e vasopressina, é provavelmente mediada pelo NO.

Em resumo, podemos concluir que, na hipertensão portal de cirróticos os dois fatores, aumento de resistência vascular e aumento do fluxo sangüíneo contribuem para a hipertensão portal, em fases mais precoces com predomínio do primeiro e em fases mais tardias com a participação dos dois. $\mathrm{O}$ tônus vascular está comprometido de maneira oposta comparandose com a circulação sistêmica e esplâncnica e a microvascularização hepática. Enquanto na sistêmica e esplâncnica o tônus está diminuído, na microvasculatura hepática o tônus está aumentado.

\section{3- OUTRAS CONSEQÜENNCIAS DA HIPER- TENSÃO PORTAL}

\section{a- Retenção de sódio e ascite}

Em cirróticos, o aumento da pressão hidrostática nos vasos esplâncnicos associado à diminuição da pressão oncótica, secundária à hipoalbuminemia, resulta em extravasamento do fluido para a cavidade peritoneal. Uma vez ultrapassada a capacidade de reabsorção do fluido pelos vasos linfáticos forma-se a ascite (Figura 7). A vasodilatação esplâncnica e a periférica atuam como ativador de sistemas neurohumorais provocando retenção de sódio e ascite (Figura 8).

\section{b- Colaterais porto-sistêmicas (Figura 9)}

A comunicação entre a circulação portal e a sistêmica, na tentativa de descomprimir o sistema portal ocorre em vários níveis. Os vasos tornam-se dilatados e tortuosos. Os locais onde mais comumente ocorrem as colaterais porto-sistêmicas são: submucosa do esôfago e estômago, submucosa do reto, parede abdominal anterior e veia renal esquerda.

\section{HIPERTENSÃO PORTAL}

FATORES EN VOL VIDOS NA FORMAÇÂO DA ASCITE

Hipoalbuminemia

Hipertensão portal

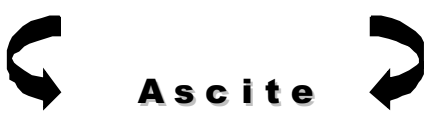

Figura 7: Fatores envolvidos na formação da ascite.

\section{MECANISMOS DE ASCITE NA CIRROSE HEPÁTICA}

resistência vascular, intra-hepática

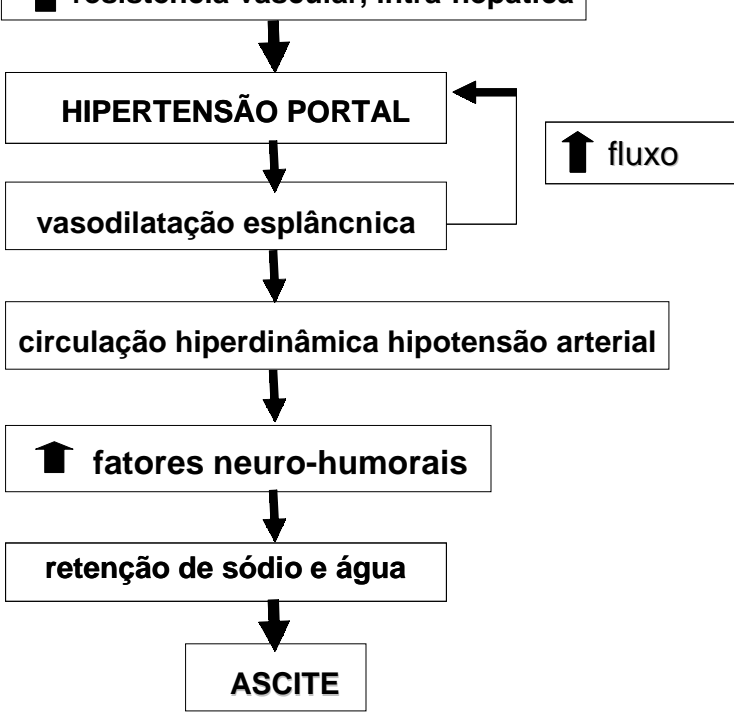

Figura 8: Mecanismos de ascite na cirrose hepática.

\section{HIPERTENSÃO PORTAL PRINCIPAIS LOCAIS DE COLATERAIS PORTO-SISTÊMICAS}

- Submucosa do esôfago (varizes de esôfago)

- Submucosa do estômago (varizes gástricas)

- Parede abdominal (circulação colateral (periférica)

- Submucosa do reto (varizes retais)

- Veia renal (shunt esplenorrenal e outros

Figura 9: Locais de formação de colaterais porto-sistêmicas na hipertensão portal. 


\section{b.1- Submucosa do esôfago e do estômago}

O maior componente das varizes de esôfago forma-se como conseqüência a anastomoses entre tributárias da veia gástrica esquerda, parte do sistema portal, e a veia ázigos, que drena para a veia cava superior. Pode haver anastomose entre os vasos periesplênicos (componentes do sistema portal) e as veias gástricas curtas que drenam para a veia cava superior constituindo a principal fonte para as varizes do plexo submucoso do estômago.

\section{b.2- Submucosa do reto}

As varizes retais formam-se como conseqüência de anastomoses entre as veias hemorroidárias superior e média (fazem parte do sistema portal) e a veia hemorroidária inferior que drena para a veia cava inferior.

\section{b.3- Parede abdominal anterior (Figura 10)}

A repermeabilização da veia umbilical e da paraumbilical permite a comunicação do ramo esquerdo da veia porta com a veia epigástrica que drena para as veias cava superior e inferior. A comunicação da veia umbilical com a veia epigástrica leva à dilatação de vasos na parede abdominal os quais drenam, a partir do umbigo, cranialmente para a veia cava superior e caudalmente para veia cava inferior. Raramente esses dois componentes são exuberantes a partir do umbigo e adquirem o aspecto semelhante à cabeça de

\section{CIRCULAÇÃO COLATERAL SUPERFICIAL}

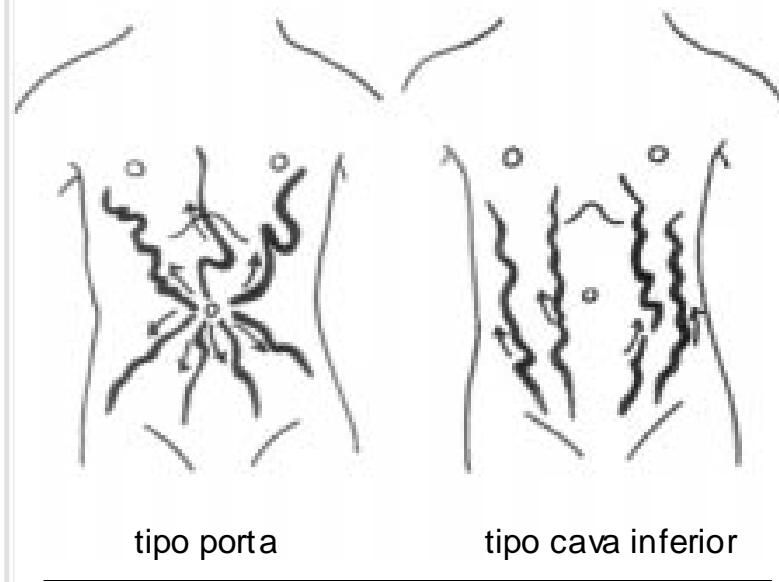

Figura 10: Circulação colateral superficial no abdômen tipo porta (A) e tipo cava, inferior. Modificado de Sherlock S \& Dooley J (2002). medusa (caput medusae) sendo que o que mais freqüentemente se observa é o componente supra- umbilical. As colaterais na parede abdominal anterior ocorrem quando existe hipertensão no ramo esquerdo da veia porta.

\section{b.4- Veia renal esquerda}

O sangue venoso, portal pode ser drenado para a veia renal esquerda diretamente pela veia esplênica ou pelas veias diafragmática, pancreática, gástrica e adrenal esquerda.

A extensa comunicação da circulação portal com a circulação sistêmica pode ser responsável por manifestações de encefalopatia hepática, uma vez que grande proporção do sangue portal é desviado do fígado e não tem contacto com as células hepáticas.

\section{c- Gastropatia hipertensiva}

A hipertensão portal pode se acompanhar de alterações na microcirculação, em qualquer parte do trato gastrointestinal. No estômago podem ser observados vasos dilatados edema e espessamento da muscularis mucosae, comunicações arteriovenosas na submucosa, mas sem significativo infiltrado inflamatório. Essas alterações compõem o que se denomina gastropatia hipertensiva.

Ectasias vasculares têm sido descritas em outras partes do trato gastrointestinal como intestino delgado e cólon.

\section{d- Esplenomegalia}

A esplenomegalia reflete alterações fibrocongestivas do baço.

\section{4- CLASSIFICAÇÃO DA HIPERTENSÃO POR- TAL}

O aumento da resistência ao fluxo portal e, portanto, causador de hipertensão portal pode ocorrer em vários níveis do sistema venoso portal e de suas vias de drenagem.

$\mathrm{Na}$ Tabela I são listadas algumas das causas de hipertensão portal classificadas de acordo com o local do aumento da resistência vascular.

Vale salientar que, em algumas situações, a obstrução pode ocorrer em mais de um local. Na cirrose alcoólica, o aumento da resistência intrahepática pode ser decorrente da distorção do lóbulo hepático e 
Tabela I: Principais causas de hipertensão portal classificadas de acordo com o local de aumento da resistência vascular

\section{a) Pré-hepática}

Trombose da veia esplênica

Trombose da veia porta

Cavernomatose da veia porta

b) Intra-hepática

Esquistossomose

Fibrose hepática congênita

Cirrose hepática

Hepatite crônica

c) Pós-hepática

Síndrome de Budd-Chiari

Malformações congênitas na veia cava inferior

Pericardite constrictiva

de estruturas vasculares nele contidas por fibrose, cicatrizes e nódulos; do edema de hepatócitos; do depósito de colágeno nos espaços de Disse (capilarização de sinusóides); da deposição de colágeno ao redor da veia centrolobular; além de mecanismos ativos de aumento da resistência vascular intrahepática, determinados por atividade nervosa e contração miofibrilar, sujeitas à intervenção farmacológica.

\section{5- MANIFESTAÇÕES CLÍNICAS (Figura 11)}

As principais manifestações clínicas da hipertensão portal são as que vêm a seguir.

a- Esplenomegalia: é uma manifestação comum da hipertensão portal, entretanto, o tamanho do baço pode ser normal. Não foi observada correlação entre o tamanho do baço e o grau de hipertensão portal. A esplenomegalia pode ser responsável por manifestações de desconforto abdominal, dor no quadrante superior esquerdo do abdômen, além de aumentar o risco de rompimento do órgão após trauma. Pode se acompanhar de manifestações consequientes ao hiperesplenismo, como leucopenia, trombocitopenia e anemia, e ser responsável por queixas relacionadas à anemia e sangramentos.

b- Colaterais portossistêmicas

b1. Circulação colateral abdominal superficial: a circulação colateral tipo porta é detectada na parede abdominal anterior e é reconhecida quando observamos vasos ingurgitados que se irradiam da cicatriz umbilical e tem fluxo ascendente acima da cicatriz umbilical e descenden- te abaixo da cicatriz umbilical. Mais frequientemente se observa o componente ascendente, o qual é mais facilmente detectado no epigástrio. Quando colocamos o estetoscópio sobre os vasos dilatados é possível ouvir-se um murmúrio (sinal de Curveilhier-Baumgarten), consequiente ao fluxo aumentado e turbilhonamento de sangue nesses vasos. Circulação colateral tipo porta na parede abdominal nos indica que existe hipertensão no ramo esquerdo da veia porta. A circulação colateral deve ser diferenciada da circulação colateral tipo cava inferior, quando o sangue é desviado para o território da veia cava superior. Nesse caso, são observados vasos com calibre aumentado, que drenam o sangue em sentido cranial desde a região infra-umbilical e, portanto, com fluxo invertido nessa região (Figura 10).

b2. Varizes de esôfago, estômago e reto: vasos calibrosos podem ser observados no trato gastrointestinal, particularmente no esôfago, estômago e reto. A manifestação mais comum é o sangramento abrupto pela ruptura das varizes. Em não cirróticos, é, freqüientemente, a primeira manifestação clínica de hipertensão portal. O sangramento das varizes esofagogástricas pode se manifestar por hematêmese e/ou melena e sinais de anemia, enquanto o das varizes retais, como enterorragia. As varizes anorretais devem ser diferenciadas das hemorróidas, cuja freqüência é semelhante em portadores e não portadores de hipertensão portal.

b3. Varizes ectópicas: podem ser observadas em cicatrizes cirúrgicas no abdômen e em enterostomias (íleo ou colostomia) e podem sangrar. Quando muito exuberante, a circulação portossistêmica pode ser responsável pelo desvio de grande parte do sangue portal para a circulação sistêmica e provocar manifestações de encefalopatia hepática, que são aliviadas quando essa comunicação é interrompida.

c- Gastroenteropatia hipertensiva: a manifestação mais importante é o sangramento digestivo.

d- Manifestações sistêmicas: manifestações do tipo circulação hipercinética, como taquicardia de repouso, íctus impulsivo e redução nos níveis da pressão arterial, podem ser observadas.

e- Ascite: a ascite pode ser uma das manifestações da hipertensão portal e é freqüentemente associada a edema de membros inferiores e da parede abdominal. Pode provocar desconforto abdominal 
ou dor abdominal vaga ou ainda, dificuldade respiratória. Se houver contaminação bacteriana do fluido ascítico (peritonite bacteriana espontânea), o paciente pode experimentar queixas de dor abdominal mais intensa, algumas vezes com dor à descompressão brusca e febre. A infecção pode precipitar quadros de encefalopatia hepática e de insuficiência renal.

f- Encefalopatia hepática: a encefalopatia hepática pode ser manifestação conseqüente à extensa circulação colateral e/ou à insuficiência hepática.

g- Outras manifestações

g1. Baqueteamento dos dedos/unhas em vidro de relógio: acredita-se que seja manifestação de hipoxemia arterial consequiente à extração prejudicada do oxigênio na periferia, à presença de comunicações arteriovenosas, além de diminuição da afinidade da hemoglobina pelo oxigênio.

g2. Manifestações pulmonares: podem estar presentes manifestações como taquipnéia e dispnéia de esforço, conseqüentes à síndrome hepatopulmonar, caracterizada por vasodilatação funcional da circulação pulmonar por resposta defeituosa à hipóxia. Pode haver ainda queixa de dispnéia de esforço relacionada à hipertensão pulmonar.

\section{6- HISTÓRIA CLÍNICA}

Alguns dados da história clínica, além das queixas relacionadas aos sintomas discutidos anteriormente, podem auxiliar na detecção do possível agente etiológico envolvido na indução da hipertensão portal.

Os antecedentes podem indicar uma das possíveis etiologias da hipertensão portal, tais como: a- hepatopatias crônicas: nesses casos é importante a informação de uso excessivo de álcool, de contacto

\section{HIPERTENSÃO PORTAL}

PRINCIPAIS MANIFESTAÇÕES CLÍNICAS<smiles>C[Te]</smiles>

Esplenomegalia com ou sem hiperesplenismo

Circulação colateral tipo porta

Varizes de esôfago (sangramento)

Ascite e peritonite bacteriana espontânea

Varizes de reto (sangramento)

Encefalopatia hepática

Figura 11: Principais manifestações clínicas na hipertensão portal.

com portadores de vírus da hepatite antecedente de hepatite e transfusões de sangue e/ou derivados procedência de locais considerados endêmicos para hepatite viral, uso de drogas injetáveis endovenosas, uso de drogas hepatotóxicas e homossexualismo. Nessas situações, podem ser detectados estigmas de doença hepática crônica, como aranhas vasculares, eritema palmar, icterícia, ginecomastia e atrofia testicular;

b- história de infecção umbilical, perinatal ou sépsis abdominal ou estados de hipercoagulabilidade podem indicar uma possível causa de hipertensão portal por obstrução da veia porta ou de veias hepáticas;

c- procedência de zona endêmica de esquistossomose pode sugerir a causa da hipertensão portal. Nos dois últimos casos $(b, c)$, comumente, observam-se manifestações de hipertensão portal, sem os estigmas de doença hepática crônica.

MARTINELLI ALC. Portal hypertension. Medicina, Ribeirão Preto, 37: 253-261, july/dec. 2004.

ABSTRACT: Portal hypertension is a common syndrome with serious clinical consequences. Some aspects of pathophysiology, causes and clinical features are discussed. The importance of making the diagnosis of the syndrome and determining the possible etiological factors involved were also discussed.

UNITERMS: Portal Hypertension. Portal System. Portal Vein . 


\section{BIBLIOGRAFIA CONSULTADA}

1 - SHERLOCK $S$ \& DOOLEY D. Diseases of the liver and biliary system. 11 th ed., Blackwell Science, Oxford, 2002. p. 147-186: The portal venous system and portal hypertension.

2 - GUPTA TK; CHEN L \& GROSZMANN RJ. Pathophysiology of portal hypertension. In: CULLEN JH, ed. Clinics in liver disease. Portal hypertension. W. B. Saunders, Philadelphia, v.1, p. 1-20, 1997

3 - BOYER TD \& HENDERSON JM. Portal hypertension and bleeding esophageal varices. In: ZAKIM D \& BOYER TD, eds. Hepatology - A textbook of liver disease. $3^{\text {rd }}$ ed., W. B. Saunders, Philadelphia, p.720-763, 1996.

4 - HADENGNE A; LEBREC D \& BENHAMOU JP. Clinical manifestation of portal hypertension. In: OKUDA K \& BENHAMOU JP, eds. Portal hypertension: Clinical and physiological aspects. Springer-Verlag, New York, p. 241-250, 1991.
5 - KOZAREK R A.; BOTOMAN V A; BREDFELDT JE; ROACH JM; PATTERSON DJ \& BALL TJ. Portal colopathy in patients with portal hypertension. Gastroenterology 101:1192-1197, 1991.

6 - MCCORMACK TT; SIM J; EYRE-BROOK I; KENNEDY H; GOEPEL $\mathrm{J} \&$ JOHNSON AG. Gastric lesions in portal hypertension: Inflammatory gastritis or congestive gastropathy? Gut 26: 12261232, 1985.

7 - NAGRAL AS; JOSHI AS; BHATIA SJ; MISTRY FP \& VORA IM. Congestive jejunopathy in portal hypertension. Gut 34: 694697, 1993.

8 - PINZANI M \& GENTILINI P. Biology of the hepatic stellate cells and their possible relevance in the pathogenesis of portal hypertension in cirrhosis. Semin Liver Disease 19: 397410, 1999.

9 - GARCIA-TSAO G. Portal hypertension. Curr Opin Gastroenterol 18:351-359, 2002. 